\title{
Thiamine supplementation in symptomatic chronic heart failure: a randomized, double-blind, placebo-controlled, cross-over pilot study
}

\author{
Andreas W. Schoenenberger · Renate Schoenenberger-Berzins • \\ Christoph Auf der Maur • Paolo M. Suter • \\ Athanasios Vergopoulos • Paul Erne
}

Received: 23 May 2011/ Accepted: 21 October 2011/Published online: 5 November 2011

(C) Springer-Verlag 2011

\begin{abstract}
Background Diuretic treatment for heart failure may lead to an increased urinary thiamine excretion and in long-term thiamine deficiency, which may further compromise cardiac function. This study evaluated the effect of high dose thiamine supplementation in heart failure patients.

Methods Nine patients with diuretic treatment for symptomatic chronic heart failure and a left ventricular ejection fraction (LVEF) $<40 \%$ were randomly assigned to receive thiamine $(300 \mathrm{mg} /$ day) or placebo for 28 days. After a wash-out of 6 weeks, the patients crossed-over to a second
\end{abstract}

A. W. Schoenenberger and R. Schoenenberger-Berzins are equally contributed to the manuscript.

Clinical Trial Registration The study is registered at clinicaltrials.gov (NCT 00770107).

Electronic supplementary material The online version of this article (doi:10.1007/s00392-011-0376-2) contains supplementary material, which is available to authorized users.

A. W. Schoenenberger

Division of Geriatrics, Department of General Internal Medicine, Inselspital, Bern University Hospital, University of Bern, Bern, Switzerland

R. Schoenenberger-Berzins - C. A. der Maur · P. Erne ( $\square)$ Department of Cardiology, Luzerner Kantonsspital, 6000 Lucerne 16, Switzerland

e-mail: Paul.Erne@ksl.ch

P. M. Suter

Clinic and Policlinic of Internal Medicine,

University Hospital of Zurich, Zurich, Switzerland

A. Vergopoulos

Department of Clinical Chemistry,

University Hospital of Zurich, Zurich, Switzerland treatment period. The primary outcome was a change in LVEF.

Results $\quad$ Mean age was $56.7 \pm 9.2$ years (range 44.9-75.4 years). Baseline LVEF was similar for both treatment groups $29.5 \%$ in the thiamine group and $29.5 \%$ in the placebo group, $P=0.911$ ). After 28 days of thiamine treatment, the LVEF increased to $32.8 \%$ which was significantly $(P=0.024)$ different from the LVEF in the placebo group (28.8\%). This corresponds to a treatment effect for LVEF of 3.9\% in absolute terms.

Conclusions This study suggests that thiamine supplementation has beneficial effects on cardiac function in patients with diuretic drugs for symptomatic chronic heart failure. Subclinical thiamine deficiency is probably an underestimated issue in these outpatients.

Keywords Thiamine $\cdot$ Heart failure - Diuretics · Cross-over studies

\section{Introduction}

In the treatment of congestive heart failure, diuretic drugs are a cornerstone of therapy. Up to $50 \%$ of an elderly population in industrialized nations will undergo long-term diuretic treatment [1]. Diuretic therapy is associated with the loss of water soluble vitamins, including vitamin $B_{1}$ (thiamine) [2-4]. A prospective hospital based study reported that diuretic treatment is associated with an increased risk for thiamine depletion [5]. Another study reported that the prevalence of thiamine deficiency in patients with heart failure was $33 \%$, though many patients were already taking thiamine supplements [6]. Thiamine is an essential cofactor in energy metabolism and thus also for normal cardiac function: thiamine deficiency is 
associated with the depression of myocardial function, congestive heart failure and wet beriberi [7-9]. Therefore, patients with congestive heart failure undergoing diuretic treatment may additionally have a compromised heart function due to thiamine deficiency.

So far, only three small studies examined the effect of a thiamine supplementation on cardiac function [10-12]. Two of these studies, of which only one was randomized, found an improvement of left ventricular function after thiamine supplementation $[10,11]$. However, in both these studies patients had moderate to severe heart failure and were inpatients on high doses of diuretics. The third study did not find a significant effect of thiamine on the clinical course of the cardiopathy, but cardiac function was not assessed by echocardiography [12]. A recent study examined the effect of a micronutrient supplementation in elderly patients with chronic heart failure, but the treatment was not restricted to thiamine alone [13]. The study also found a significant improvement of left ventricular function. We, therefore, intended to investigate the effect of thiamine on cardiac function in outpatients with moderate chronic heart failure in a randomized, controlled, doubleblind study using echocardiographic as well as clinical endpoints.

\section{Methods}

\section{Study population}

All outpatients at the Lucerne Hospital, who were treated with diuretics for symptomatic chronic heart failure, were eligible for this study. Congestive heart failure was defined as left ventricular ejection fraction (LVEF) below $40 \%$ and the presence of at least one of the following four criteria: (a) shortness of breath or orthopnea, (b) positive hepatojugular reflex, (c) interstitial transudation on chest radiography, or (d) elevated brain natriuretic peptide (BNP) ( $\geq 39 \mathrm{ng} / \mathrm{L}$ ). Heart failure was considered stable if symptoms and body weight remained unchanged for at least 14 days. Patients with acute heart failure were not eligible for this study because of the foreseeable need for further changes in medication. Patients on vitamin supplements, patients with renal failure (creatinine $>250 \mu \mathrm{mol} / \mathrm{L}$ ) and fertile women were excluded from study participation. Screening for eligibility was performed during routine outpatient visits. Due to logistic reasons, screening for eligibility of a new patient was started only after a previous patient completed the study protocol. Informed written consent was obtained from all eligible patients willing to participate in the study. The study was approved by the local ethical committee and complies with the Declaration of Helsinki.

\section{Intervention}

A randomized, double-blind, placebo-controlled, two-period cross-over design was performed. The study coordination centre at the Bern University Hospital randomly assigned participating patients to one of the two treatment groups. The random allocation sequence was generated by a computerized random number generator. The treatment consisted of either thiamine $(300 \mathrm{mg} /$ day $)$ or placebo ( 1 tablet/day) for 28 days. Both preparations (thiamine and placebo) were produced by the same company (Streuli Pharmaceutical Company, Uznach, Switzerland) to ensure identical size, shape and colour. The study coordination centre at the Bern University Hospital provided the allocated treatment in sequentially numbered containers to the care providers at the Lucerne Hospital. By separating the randomization centre (Bern University Hospital) and examination site (Lucerne Hospital), participating patients and physicians assessing outcomes were blinded to the treatment allocation.

The first treatment period of 28 days was followed by a wash-out period of 6 weeks to eliminate any carry-over effects. After the wash-out, the patient was enrolled for the second treatment period. The second treatment period was identical to the first, except for the medication which was reversed (placebo or thiamine).

Prescriptions for other medications were continued throughout the study. A change in medication was allowed whenever it was required by clinical circumstances.

\section{Examinations and follow-up}

Patients were examined on days 1, 8, 15 and 29 of each treatment period. Treatment with either thiamine or placebo was started on day 2. Functional status (general health, dyspnea during day, night and exercise) was assessed on days 1, 8, 15 and 29 using visual analogue scales. A 6-min walking test was performed on days 1, 8, 15 and 29. In this test, patients had to walk on a predefined route for $6 \mathrm{~min}$ and the distance walked was recorded (in $\mathrm{m}$ ). Assessment of functional status was completed by a 24-h steps counter (pedometer) at home on days 2, 3, 27 and 28. Dietary intake at home was recorded on a protocol on days 2, 3 and 4. BNP was measured on days $1,8,15$ and 29. Creatinine, potassium, sodium, magnesium, ferritin and haemoglobin were measured on days 1 and 29. Free thiamine was measured on days $1,8,15$ and 29 by high-pressure liquid chromatography (normal range $28-85 \mathrm{ng} / \mathrm{mL}$ ). An ECG was recorded on days 1 and 29. Transthoracic echocardiography was performed on days $1,8,15$ and 29 by the same operator. LVEF was determined on two- and four-chamber views using the modified biplane Simpson method. The operator was blinded for the treatment. 


\section{Outcomes}

The primary interest of the study was a change in echocardiographic findings, particularly the LVEF. Other outcomes were functional status as assessed by visual analogue scales, the 6-min walking test, pedometer steps and the level of B-type natriuretic peptide.

Statistical methods

Sample size was calculated supposing a relative increase of the LVEF of $6 \%$ and a standard deviation of the LVEF of $7 \%$ [11]. With an alpha-error of 0.05 and a power of 0.80 , a sample size of 22 was found for a parallel group design. It is presumed that with the cross-over design, the total number of subjects is lower than half (probably one quarter) of the total number required for a parallel group study with the same power.

Data were analysed using Stata software (Stata 11.0, StataCorp LP, College Station, TX, USA). A $P$ value $<0.05$ was considered significant. For two-group comparisons, paired $t$ test was used after checking for normal distribution; Mann-Whitney rank-sum test was used for non-normally distributed continuous variables. An analysis of variance was performed to confirm the effect of the treatment on LVEF.

\section{Results}

Of 16 eligible patients, $6(37.5 \%)$ patients declined participation due to refusal to take an additional drug or inability to come to the frequent follow-up examinations (Fig. 1). Between 18 June 2004 and 21 May 2008, ten patients were randomized to thiamine or placebo and completed the first treatment period. One patient withdrew his consent during the wash-out period because he was no longer willing to travel the distance to the hospital for the frequent follow-up examinations. Therefore, nine patients completed the second treatment period and were included in the analysis.

The baseline characteristics of the nine participating patients are shown in Table 1. The mean age was $56.7 \pm 9.2$ years (range 44.9-75.4 years). As a cause for reduced LVEF and heart failure, coronary artery disease (CAD) was found in six patients $(67 \%)$ and dilative cardiomyopathy in three patients $(33 \%)$. Dilative cardiomyopathy was related to excess alcohol consumption in one patient and was of unknown origin in two patients. In both patients, CAD was excluded by angiography. CAD was combined with valvular and hypertensive heart disease in one patient. All patients had a prescription for an angiotensin-converting enzyme inhibitor or an angiotensin

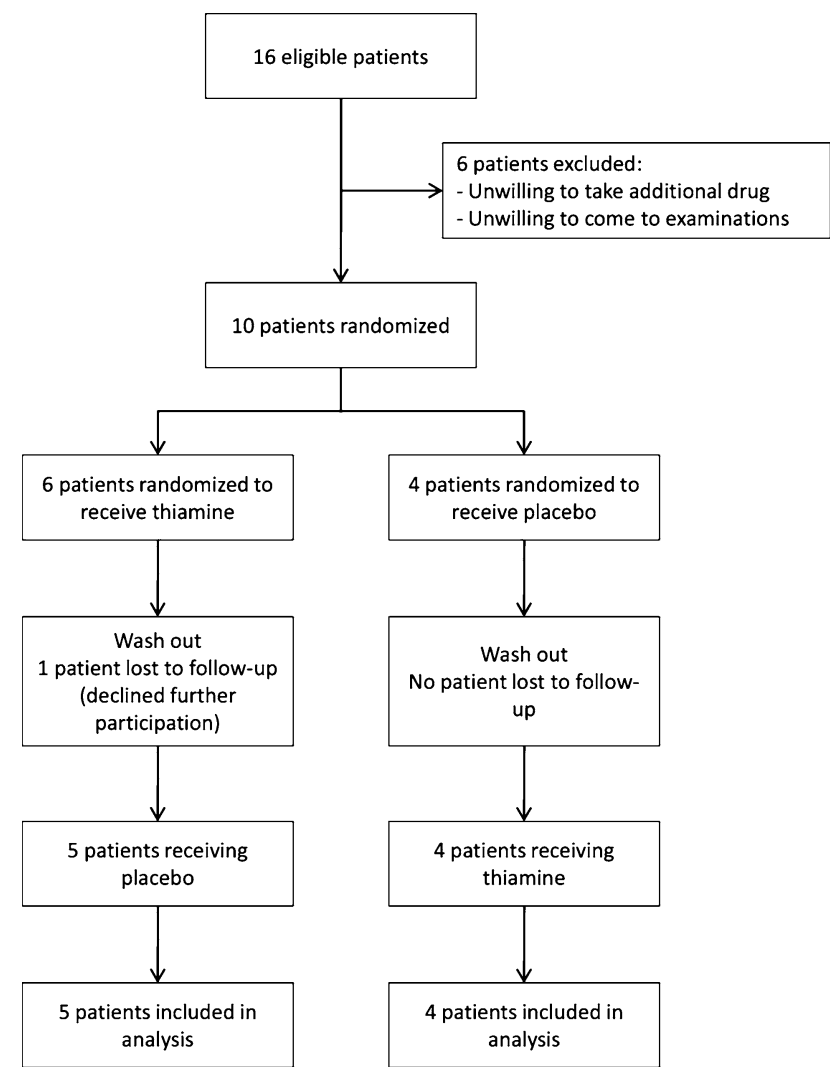

Fig. 1 Patient flow

receptor blocker and a diuretic. The prescriptions for medications other than thiamine or placebo remained unchanged throughout the study in all patients except for one patient in whom the dose of the diuretic drug was temporarily increased due to swollen legs.

During thiamine treatment, free thiamine increased from $73 \pm 10 \mathrm{ng} / \mathrm{mL}$ (range $60-91 \mathrm{ng} / \mathrm{mL}$ ) on day 1 to $132 \pm 29 \mathrm{ng} / \mathrm{mL} \quad$ (range $102-199 \mathrm{ng} / \mathrm{mL}$ ) on day 8 $(P<0.001)$. The percentage increase between day 1 and day 8 in the individual patient was minimally $140 \%$ and maximally $219 \%$. During thiamine treatment, free thiamine remained on a high level on days 15 and 29 (133 $\pm 28 \mathrm{ng} /$ $\mathrm{mL}$ and $132 \pm 33 \mathrm{ng} / \mathrm{mL}$, respectively). No increase in free thiamine was observed during placebo treatment. Compliance with the prescribed treatment was therefore $100 \%$.

In the five patients having received thiamine during the first treatment period, free thiamine decreased to $75 \pm 4 \mathrm{ng} / \mathrm{mL}$ (range $70-81 \mathrm{ng} / \mathrm{mL}$ ) at day 1 of the second treatment period. The LVEF in these five patients also decreased from $33.8 \%$ at last follow-up during the first treatment period to $30.6 \%$ at the beginning of the second treatment period. A relevant period effect was, therefore, excluded and both treatment periods were combined for the analysis of outcomes. 
Table 1 Baseline characteristics

\begin{tabular}{|c|c|}
\hline Characteristics & $\begin{array}{l}\text { Study participants } \\
(N=9)\end{array}$ \\
\hline Age, mean $\pm \mathrm{SD}$ (years) & $56.7 \pm 9.2$ \\
\hline Female sex, $n(\%)$ & $2(22)$ \\
\hline Weight, mean $\pm \mathrm{SD}(\mathrm{kg})$ & $81 \pm 18$ \\
\hline Height, mean $\pm \mathrm{SD}(\mathrm{cm})$ & $173 \pm 9$ \\
\hline Body mass index, mean $\pm \mathrm{SD}\left(\mathrm{kg} / \mathrm{m}^{2}\right)$ & $27 \pm 6$ \\
\hline $\begin{array}{l}\text { Blood pressure systolic, mean } \pm \text { SD } \\
(\mathrm{mmHg})\end{array}$ & $122 \pm 18$ \\
\hline $\begin{array}{l}\text { Blood pressure diastolic, mean } \pm \text { SD } \\
(\mathrm{mmHg})\end{array}$ & $74 \pm 12$ \\
\hline Heart rate, mean $\pm \mathrm{SD}$ (beats/min) & $74 \pm 14$ \\
\hline Creatinine, mean $\pm \mathrm{SD}(\mu \mathrm{mol} / \mathrm{L})$ & $100 \pm 23$ \\
\hline \multicolumn{2}{|l|}{ Cardiovascular risk factors ${ }^{\mathrm{a}}$} \\
\hline Hypertension, $n(\%)$ & $4(44)$ \\
\hline Dyslipidemia, $n(\%)$ & $6(67)$ \\
\hline Diabetes, $n(\%)$ & $1(11)$ \\
\hline Smoking, $n(\%)$ & $6(67)$ \\
\hline Family history of CAD, $n(\%)$ & $3(33)$ \\
\hline \multicolumn{2}{|l|}{ Heart disease ${ }^{\mathrm{b}}$} \\
\hline $\mathrm{CAD}, n(\%)$ & $6(67)$ \\
\hline Valvular heart disease, $n(\%)$ & $1(11)$ \\
\hline Hypertensive heart disease, $n(\%)$ & $1(11)$ \\
\hline Dilative cardiomyopathy, $n(\%)$ & $3(33)$ \\
\hline \multicolumn{2}{|l|}{ Signs of heart failure } \\
\hline Dyspnea or orthopnea, $n(\%)$ & $7(78)$ \\
\hline Hepatojugular reflex positive, $n(\%)$ & $0(0)$ \\
\hline $\begin{array}{l}\text { Interstitial transudation on chest } \\
\text { radiography, } n(\%)\end{array}$ & $0(0)$ \\
\hline BNP elevated ( $\geq 39 \mathrm{ng} / \mathrm{L}), n(\%)$ & $5(56)$ \\
\hline \multicolumn{2}{|l|}{ Drug therapy } \\
\hline $\mathrm{ACE}$ inhibitor or $\mathrm{ARB}, n(\%)$ & $9(100)$ \\
\hline Loop or thiazid diuretic, $n(\%)$ & $8(89)$ \\
\hline Aldosterone antagonist, $n(\%)$ & $4(44)$ \\
\hline Beta blocker, $n(\%)$ & $8(89)$ \\
\hline
\end{tabular}

$A C E$ angiotensin-converting enzyme, $A R B$ angiotensin receptor blocker, $B N P$ brain natriuretic peptide, $C A D$ coronary artery disease, $S D$ standard deviation

a Definition according to international guidelines

${ }^{b}$ More than one diagnosis per patient allowed

\section{Outcomes}

Results of main outcomes at first assessment on day 1 and last follow-up on day 29 of both cross-over treatment periods combined during thiamine or placebo treatment are summarized in Table 2. At baseline (first assessment on day 1), outcome variables were similar between thiamine and placebo group with no significant differences between the two treatment groups. The main finding was that LVEF was significantly different between the thiamine and the placebo group at last follow-up on day 29 (32.8\% with thiamine and $28.8 \%$ with placebo, $P=0.024$ ) (Fig. 2). This corresponds to a treatment effect for LVEF of $3.9 \%$ in absolute terms. For the other outcomes, no significant differences were found at the last follow-up for the between-treatment group comparison. However, the 24-h steps counter measurement showed a nearly significant improvement during thiamine treatment.

In addition to the between-treatment group comparisons in Table 2, the change of the outcomes between day 1 and day 29 within each treatment group was analyzed. The LVEF increase during thiamine from 29.5 to $32.8 \%$ was significant $(P=0.015)$. The decrease of the right atrium area during thiamine from 16.7 to $14.8 \mathrm{~cm}^{2}$ was significant $(P=0.026)$. The improvement of the 6-min walking test from 549 to $624 \mathrm{~m}$ was close to significance during thiamine treatment $(P=0.084)$. No significant changes in outcomes between baseline and follow-up assessment were found during placebo treatment.

An analysis of variance was performed to confirm the effect of the treatment on LVEF. As dependent variable the change in LVEF between first and last follow-up was chosen. Age, sex, the presence of a CAD or dilative cardiomyopathy, and the treatment (thiamine or placebo) were selected as independent variables. Of these variables, only the treatment had a significant effect on the change in LVEF $(F$ ratio $=6.09, P=0.028)$.

\section{Discussion}

This study shows that a treatment with $300 \mathrm{mg}$ thiamine per day improves cardiac function as measured by echocardiography in patients, who were treated with diuretics for symptomatic chronic heart failure. In particular, LVEF improves with thiamine. The improvement of cardiac function probably has beneficial effects on functional status as measured by the 6-min walking test and the 24-h steps counter.

Our study is in agreement with the two previous studies that found an improvement of left ventricular function after thiamine supplementation [10, 11]. In addition to these studies, our study shows that the improvement of heart function may also be achieved in patients with symptomatic chronic heart failure and that this improvement probably has a beneficial effect on functional status.

The study was performed in a two-period cross-over design. This design was selected because the interindividual variability of the measured outcomes was expected to be high in comparison to the beneficial effect of the treatment in the individual patient. Consequently, a crossover design was more efficient than a parallel group design. 
Table 2 Results of main outcomes at first assessment on day 1 and last follow-up on day 29 of both cross-over treatment periods combined and separated for each treatment group (thiamine and placebo)

\begin{tabular}{|c|c|c|c|c|c|c|}
\hline \multirow[t]{2}{*}{ Outcomes } & \multicolumn{3}{|c|}{$\begin{array}{l}\text { At first assessment (day 1) of both treatment } \\
\text { periods combined }\end{array}$} & \multicolumn{3}{|c|}{$\begin{array}{l}\text { At last follow-up (day 29) of both treatment } \\
\text { periods combined }\end{array}$} \\
\hline & $\begin{array}{l}\text { Thiamine } \\
(N=9)\end{array}$ & $\begin{array}{l}\text { Placebo } \\
(N=9)\end{array}$ & $P$ value $^{\mathrm{a}}$ & $\begin{array}{l}\text { Thiamine } \\
(N=9)\end{array}$ & $\begin{array}{l}\text { Placebo } \\
(N=9)\end{array}$ & $P$ value $^{\mathrm{a}}$ \\
\hline Dyspnea during day, mean \pm SE, VAS ${ }^{b}$ & $1.9 \pm 0.8$ & $2.2 \pm 0.9$ & 0.963 & $1.5 \pm 0.8$ & $1.7 \pm 0.9$ & 0.617 \\
\hline Dyspnea during night, mean \pm SE, VAS ${ }^{b}$ & $0.7 \pm 0.7$ & $0.8 \pm 0.8$ & 0.634 & $0.8 \pm 0.8$ & $0.6 \pm 0.5$ & 0.634 \\
\hline Weight, mean $\pm \mathrm{SE}(\mathrm{kg})$ & $81 \pm 6$ & $81 \pm 6$ & 0.791 & $80 \pm 6$ & $80 \pm 6$ & 0.782 \\
\hline 6-min walking test, mean $\pm \mathrm{SE}(\mathrm{m})$ & $549 \pm 31$ & $605 \pm 28$ & 0.157 & $624 \pm 28$ & $614 \pm 24$ & 0.689 \\
\hline 24-h steps counter, mean \pm SE (steps/day) & $7052 \pm 1529$ & $6596 \pm 1337$ & 0.930 & $8596 \pm 1270$ & $5944 \pm 1069$ & 0.089 \\
\hline $\mathrm{BNP}$, mean $\pm \mathrm{SE}(\mathrm{ng} / \mathrm{L})$ & $166 \pm 71$ & $183 \pm 86$ & 0.508 & $165 \pm 72$ & $170 \pm 64$ & 0.402 \\
\hline LVEF, mean \pm SE $(\%)$ & $29.5 \pm 2.4$ & $29.5 \pm 2.5$ & 0.911 & $32.8 \pm 2.7$ & $28.8 \pm 2.4$ & 0.024 \\
\hline $\mathrm{LVEDV}$, mean $\pm \mathrm{SE}(\mathrm{mL})$ & $197 \pm 25$ & $194 \pm 30$ & 0.757 & $188 \pm 36$ & $169 \pm 24$ & 0.560 \\
\hline Area of left atrium, mean $\pm S E\left(\mathrm{~cm}^{2)}\right.$ & $22.2 \pm 1.4$ & $21.2 \pm 1.8$ & 0.442 & $21.0 \pm 1.2$ & $21.3 \pm 1.8$ & 0.871 \\
\hline Area of right atrium, mean $\pm \mathrm{SE}\left(\mathrm{cm}^{2}\right)$ & $16.7 \pm 1.0$ & $17.3 \pm 1.8$ & 0.780 & $14.8 \pm 0.7$ & $15.9 \pm 1.2$ & 0.289 \\
\hline Thickness of IVS, mean \pm SE $(\mathrm{mm})$ & $8.9 \pm 0.3$ & $9.0 \pm 0.4$ & 0.786 & $9.4 \pm 0.3$ & $8.7 \pm 0.4$ & 0.215 \\
\hline
\end{tabular}

$B N P$ brain natriuretic peptide, IVS interventricular septum, $L V E D V$ left ventricular end-diastolic volume, $L V E F$ left ventricular ejection fraction, $S E$ standard error, VAS visual analogue scale

${ }^{a} P$ value for the between-treatment group comparison

b Dyspnea measured by visual analogue scales (range from 0 for no dyspnea to 10 for maximal dyspnea)

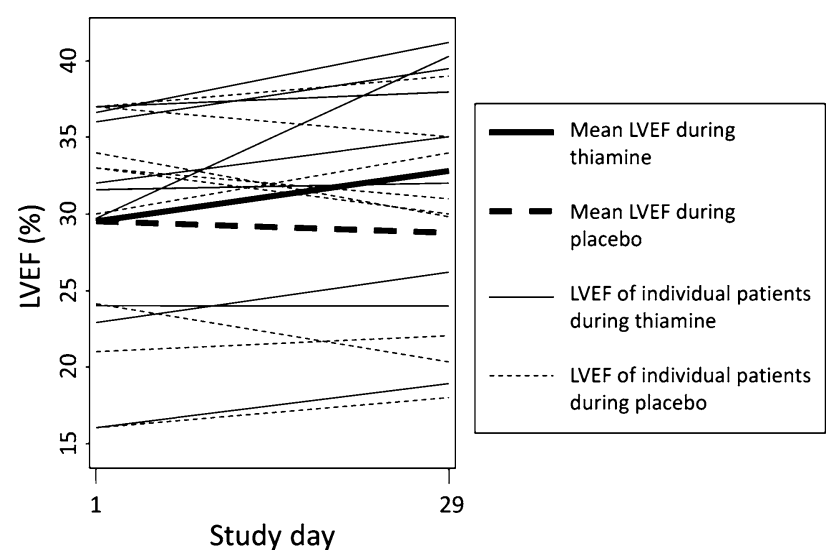

Fig. 2 Changes in the left ventricular ejection fraction (LVEF) between first assessment on day 1 and last follow-up on day 29 according to treatment group (thiamine or placebo). Mean LVEF as well as LVEF of individual patients is displayed

For thiamine, a pharmacological dose of $300 \mathrm{mg} /$ day was selected. Although this dosage exceeds daily requirement by far, a high dosage was considered essential to guarantee a measurable effect. In view of the characteristics of thiamine metabolism, a wash-out period of 6 weeks was considered adequate for the elimination of a carry-over effect. The thiamine and LVEF measurements at the beginning of the second treatment period in the five patients having received thiamine during the first treatment period confirmed that a wash-out period of 6 weeks was sufficient.

This study has several limitations. First, the sample size of nine patients is very small and the follow-up period was comparatively short. It was too small to show significant differences between the treatment groups for other outcomes than LVEF [14]. However, a significant effect of thiamine on these outcomes may not be expected, according to the a priori sample size calculation. Due to the short follow-up periods, we cannot estimate the effect of thiamine on further important outcomes such as mortality or morbidity [15-18]. Therefore, our study only suggests potential usefulness of thiamine which needs to be confirmed in a larger study. Second, the thiamine dose was in the pharmacological range since the vitamin was given as a drug and not as a nutritional supplement. In future studies dose-response effects need to be assessed. Third, we measured free thiamine which was within normal range on day 1 (normal range $28-85 \mathrm{ng} / \mathrm{mL}$ ). However, free thiamine levels may be normal despite subclinical thiamine deficiency. For the assessment of subclinical thiamine deficiency measurement of enzymatic activity (such as the transketolase activity) would have been more appropriate [5].

The authors believe that this study has research implications. Larger and longer studies investigating potential beneficial and also harmful effects of thiamine in patients with symptomatic chronic heart failure, but also in patients with acute heart failure, are required. In due consideration of the beneficial effects found in this and the previous small studies, the clinical implications of a large study potentially are crucial $[10,11]$. However, it is too early to derive clinical implications from this pilot study. Furthermore, it would be interesting to examine the effect of thiamine 
supplementation in patients with diuretic resistance. Future studies should also examine very old patients as the incidence of congestive heart failure, thiamine malnutrition and diuretic treatment increases with age [19-22].

In conclusion, this study shows that the thiamine supplementation has beneficial effects on cardiac function in patients with symptomatic chronic heart failure. In view of the safety profile of thiamine, a therapeutic thiamine trial in difficult to treat patients with congestive heart failure seems to be warranted and timely.

Acknowledgments Andreas Schoenenberger was supported by a Forschungskolleg Geriatrie Grant from the Robert Bosch Foundation, Stuttgart, Germany.

\section{References}

1. van-Kraaij DJ, Jansen RW, de-Gier JJ, Gribnai FW, Hoefnagels WH (1998) Prescription patterns of diuretics in Dutch community-dwelling elderly patients. Br J Clin Pharmacol 46:403-407

2. Yui Y, Itokawa Y, Kawai C (1980) Furosemide-induced thiamine deficiency. Cardiovasc Res 14:537-540

3. Rieck J, Halkin H, Almog S, Seligman H, Lubetsky A, Olchovsky D, Ezra D (1999) Urinary loss of thiamine is increased by low doses of furosemide in healthy volunteers. J Lab Clin Med 134:238-243

4. Suter PM, Vetter W (2000) Diuretics and vitamin B1: are diuretics a risk factor for thiamin malnutrition? Nutr Rev 58:319-323

5. Suter PM, Haller J, Hany A, Vetter W (2000) Diuretic use: a risk factor for subclinical thiamine deficiency in elderly patients. J Nutr Health Aging 4:69-71

6. Hanninen SA, Darling PB, Sole MJ, Barr A, Keith ME (2006) The prevalence of thiamin deficiency in hospitalized patients with congestive heart failure. J Am Coll Cardiol 47:354-361

7. Katare RG, Caporali A, Oikawa A, Meloni M, Emanueli C, Madeddu P (2010) Vitamin B1 analog benfotiamine prevents diabetes-induced diastolic dysfunction and heart failure through Akt/Pim-1-mediated survival pathway. Circ Heart Fail 3:294-305

8. Gioda CR, Roman-Campos D, Carneiro-Júnior MA, da Silva KA, de Souza MO, Mendes LJ, Natali AJ, Cruz JS (2009) Impaired cellular contractile function in thiamine-deficient rat cardiomyocytes. Eur J Heart Fail 11:1126-1128

9. Abelmann WH, Lorell BH (1989) The challenge of cardiomyopathy. J Am Coll Cardiol 13:1219-1239

10. Seligmann H, Halkin H, Rauchfleisch S, Kaufmann N, Motro M, Vered Z, Ezra D (1991) Thiamine deficiency in patients with congestive heart failure receiving long-term furosemide therapy: a pilot study. Am J Med 91:151-155

11. Shimon I, Almog S, Vered Z, Seligmann H, Shefi M, Peleg E, Rosenthal T, Motro M, Halkin H, Ezra D (1995) Improved left ventricular function after thiamine supplementation in patients with congestive heart failure receiving long-term furosemide therapy. Am J Med 98:485-490

12. Pfitzenmeyer P, Guilland JC, d'Athis P, Petit-Mernier C, Gaudet M (1994) Thiamine status of elderly patients with cardiac failure including the effects of supplementation. Int J Vitam Nutr Res 64:113-118

13. Witte KK, Nikitin NP, Parker AC, von Haehling S, Volk HD, Anker SD, Clark AL, Cleland JG (2005) The effect of micronutrient supplementation on quality-of-life and left ventricular function in elderly patients with chronic heart failure. Eur Heart $\mathbf{J}$ 26:2238-2244

14. Luers C, Wachter R, Kleta S, Uhlir M, Koschack J, Scherer M, Binder L, Herrmann-Lingen C, Zapf A, Kulle B, Kochen MM, Pieske B (2010) Natriuretic peptides in the detection of preclinical diastolic or systolic dysfunction. Clin Res Cardiol 99:217-226

15. Schoenenberger AW, Kobza R, Jamshidi P, Zuber M, Abbate A, Stuck AE, Pfisterer M, Erne P (2009) Sudden cardiac death in patients with silent myocardial ischemia after myocardial infarction (from the Swiss Interventional Study on Silent Ischemia Type II [SWISSI II]). Am J Cardiol 104:158-163

16. Saguner AM, Dür S, Perrig M, Schiemann U, Stuck AE, Bürgi U, Erne P, Schoenenberger AW (2010) Risk factors promoting hypertensive crises: evidence from a longitudinal study. Am J Hypertens 23:775-780

17. Gorelik O, Almoznino-Sarafian D, Shteinshnaider M, Alon I, Tzur I, Sokolsky I, Efrati S, Babakin Z, Modai D, Cohen N (2009) Clinical variables affecting survival in patients with decompensated diastolic versus systolic heart failure. Clin Res Cardiol 98:224-232

18. Karapolat H, Demir E, Bozkaya YT, Eyigor S, Nalbantgil S, Durmaz B, Zoghi M (2009) Comparison of hospital-based versus home-based exercise training in patients with heart failure: effects on functional capacity, quality of life, psychological symptoms, and hemodynamic parameters. Clin Res Cardiol 98:635-642

19. Schoenenberger AW, Radovanovic D, Stauffer JC, Windecker S, Urban P, Eberli FR, Stuck AE, Gutzwiller F, Erne P, Acute Myocardial Infarction in Switzerland Plus Investigators (2008) Age-related differences in the use of guideline-recommended medical and interventional therapies for acute coronary syndromes: a cohort study. J Am Geriatr Soc 56:510-516

20. Kamp O, Metra M, de Keulenaer GW, Pieske B, Conraads V, Zamorano J, Huysse L, Vardas PE, Böhm M, Dei Cas L (2010) Effect of the long-term administration of nebivolol on clinical symptoms, exercise capacity and left ventricular function in patients with heart failure and preserved left ventricular ejection fraction: background, aims and design of the ELANDD study. Clin Res Cardiol 99:75-82

21. Conen D, Chae CU, Guralnik JM, Glynn RJ (2010) Influence of blood pressure and blood pressure change on the risk of congestive heart failure in the elderly. Swiss Med Wkly 140:202-208

22. Muzzarelli S, Tobler D, Leibundgut G, Schindler R, Buser P, Pfisterer ME, Brunner-La Rocca HP (2009) Detection of intake of nonsteroidal anti-inflammatory drugs in elderly patients with heart failure. How to ask the patient? Swiss Med Wkly 139:481-485 